\title{
Neuroendocrine Mechanisms Underlying the Intergenerational Transmission of Maternal Behavior and Infant Abuse in Rhesus Macaques
}

\author{
Dario Maestripieri ${ }^{1}$
}

\section{Summary}

Parenting style in rhesus macaques (Macaca mulatta) can vary dramatically among individuals along the two orthogonal dimensions of maternal protectiveness and maternal rejection. High rates of maternal rejection can be accompanied by infant abuse. We investigated the effects of exposure to variable parenting styles on offspring behavioral and neuroendocrine development to identify the possible mechanisms underlying the intergenerational transmission of maternal behavior and infant abuse. Forty-three non-crossfostered male and female infants and 16 crossfostered female infants were followed through their first three years of life or until they reproduced for the first time. Half of the infants were reared by abusive mothers and half by nonabusive controls. Cerebral spinal fluid (CSF) concentrations of the serotonin metabolite, 5-HIAA, were measured at six-month intervals. Abused infants were rejected more by their mothers than controls, and infants exposed to higher rates of maternal rejection had significantly lower CSF 5-HIAA in the first three years of life. When the crossfostered females gave birth for the first time, their rates of maternal rejection matched those of their foster mothers and were negatively correlated with CSF 5-HIAA. Approximately half of the females reared by the abusive mothers exhibited abusive parenting, whereas none of the females reared by controls did. The abused females who became abusive mothers had lower CSF 5-HIAA than the abused females who did not. These findings provide evidence that maternal rejection and infant abuse are transmitted across generations and suggest that experience-induced, long-term alterations in brain serotonergic function may play an important role in the intergenerational transmission of normal and abnormal parenting.

\section{Introduction}

Studies of macaques and other Old World monkeys have shown that most variability in parenting style occurs along the two orthogonal dimensions of maternal protectiveness and rejection (Tanaka 1989; Schino et al. 1995; Fairbanks 1996; Maestripieri 1998a). The maternal protectiveness dimension includes variation in the extent to which the mother physically restrains her infant, initiates proximity and contact, and cradles

1 Department of Comparative Human Development, The University of Chicago, Chicago, IL 60637, e-mail: dario@uchicago.edu 
and grooms her infant. The maternal rejection dimension includes the extent to which the mother limits the timing and duration of contact, suckling, or carrying. Although maternal behavior changes as a function of infant age and the mother's own age and experience, individual differences in parenting style are generally consistent over time and across infants (Hinde and Spencer-Booth 1971; Fairbanks 1996).

Studies of macaques and vervet monkeys have shown that exposure to a particular parenting style in infancy can have long-term effects on the offspring's behavior. For example, infants reared by highly rejecting mothers generally develop independence at an earlier age than infants reared by mothers with low rejection levels (Simpson 1985; Simpson and Simpson 1985; Simpson et al. 1989; Simpson and Datta 1990). In contrast, infants reared by more protective mothers appear to be delayed in the acquisition of their independence and are relatively fearful and cautious when faced with challenging situations (Fairbanks and McGuire 1987, 1988, 1993; Vochteloo et al. 1993). Effects of parenting style on offspring behavior can extend into adulthood (Fairbanks and McGuire 1988, 1993; Schino et al. 2001; Bardi et al. 2005; Bardi and Huffman 2006; Maestripieri et al. 2006b). These effects have also been demonstrated with experimental manipulations of maternal behavior (Vochteloo et al. 1993) and with infant crossfostering studies (Maestripieri 2005,b; Maestripieri et al. 2006b). Parenting style has also been shown to affect the offspring's parenting behavior in adulthood, as there are often significant similarities in maternal rejection between mothers and daughters (Fairbanks 1989; Berman 1990; Maestripieri 2005a; Maestripieri et al. 2007). The mechanisms underlying the intergenerational transmission of parenting style in monkeys, however, are still poorly understood.

\section{Brain Serotonin and Naturally Occurring Variation in Primate Maternal Behavior}

In the past decade, we have conducted a series of studies investigating the neurobiological and neuroendocrine mechanisms underlying the cross-generational effects of naturally occurring variation in parenting style, including infant abuse, in rhesus macaques. The project was conducted with a population of approximately 1,500 rhesus macaques living at the Field Station of the Yerkes National Primate Research Center in Lawrenceville, GA. Previous studies had shown that 5 to $10 \%$ of adult females in this population abuse their offspring and that abusive parenting runs in families, being present in some matrilines for more than six to seven generations and completely absent in others (Maestripieri et al. 1997; Maestripieri 1998b; Maestripieri and Carroll 1998a,b). At the Yerkes Field Station, the rhesus macaques are housed in large outdoor corrals, where they live in social groups of naturalistic size and composition. In our research project, the individuals are studied in their own social groups, where they have the opportunity to express naturally occurring variation in behavioral tendencies. The monkeys are trained for capture and handling, so that procedures involving experimental testing and collection of biological samples are generally brief and the subjects are immediately returned to their groups for observation.

The project involved the longitudinal study of 16 females that were crossfostered at birth between abusive and nonabusive mothers, along with 43 males and females that were born and raised by their biological mothers, half of which were abusive and half nonabusive. In addition to studying the social development and behavioral reactivity 
to stress of offspring exposed to variable maternal behavior in infancy, we assessed the development of hypothalamic-pituitary-adrenal (HPA) function and the functionality of brain monoamine systems, such as serotonin, dopamine, and norepinephrine, by measuring the plasma concentrations of ACTH and cortisol in a variety of experimental conditions, and by measuring the CSF concentrations of serotonin, dopamine, and norepinephrine metabolites (5-HIAA, HVA, and MHPG, respectively) at six-month intervals (see Maestripieri et al. 2006a, for details of the experimental procedures). A subset of infants and their mothers was also genotyped for the polymorphism in the serotonin transporter gene (Lesch et al. 1996), which has been shown to modulate the effects of early experience on adult behavior and psychopathology in both humans and rhesus macaques. In particular, individuals with the short $(s)$ allele of this gene are more likely to develop anxiety disorders and dysregulation of the HPA axis as a result of early adverse experience than individuals with the long $(l)$ allele (Lesch et al. 1996; Bennett et al. 2002; Caspi et al. 2002, 2003; Barr et al. 2004a,b). Analyses of the hormonal data are still in progress; therefore, the rest of this chapter will focus on the behavioral and brain monoamine data, with particular emphasis on serotonin.

We found that abusive mothers were significantly more likely to carry the $s$ allele of the serotonin transporter gene than nonabusive mothers; however, there was no significant difference in the prevalence of the $l$ and $s$ alleles between the offspring of abusive and nonabusive mothers. Individual differences in the CSF concentrations of 5 -HIAA in the offspring measured at $6,12,18,24,30$, and 36 months of age were highly stable over time (see also Higley et al. 1992). Infants that were heterozygous ( $l / s$ genotype) or homozygous for the long or the short allele ( $l / l$ and $s / s$ genotype) of the serotonin transporter gene did not differ significantly from each other in their CSF concentrations of 5-HIAA. Moreover, we found no significant variation in CSF concentrations of 5-HIAA in relation to infant abuse experienced in the first three months of life (abuse is concentrated in the first month and generally ends by the end of the third month; Maestripieri et al. 2006b). Therefore, we focused our analysis of offspring development on the effects of exposure to variable parenting style in infancy.

We found stable individual differences in many measures of maternal behavior in the first six postpartum months and, similar to previous studies, we found that these measures clustered around two factors, or parenting style dimensions: protectiveness and rejection. We obtained composite measures of these two dimensions and classified all mothers in our sample as being high or low in protectiveness and high or low in rejection depending on whether their scores were above or below the median value for the composite measures.

The individuals exposed to high rates of maternal rejection in infancy had significantly lower CSF concentrations of 5-HIAA across their first three years of life than the individuals exposed to low rates of maternal rejection (Maestripieri et al. 2006a). Data were analyzed separately for crossfostered and non-crossfostered individuals. and a similar relation between maternal rejection and CSF 5-HIAA was found in both groups, suggesting that this association was not due to genetic similarities between mothers and offspring. In contrast, there were no differences in CSF 5-HIAA between offspring reared by high and low protectiveness mothers. Long-term effects of early experience on the development of the brain serotonergic system have also been reported in other studies of rhesus macaques (Kraemer et al. 1989; Higley et al. 1992; Shannon et al. 2005) as well as rodents (e.g., Ladd et al. 1996; Gardner et al. 2005). 
Exposure to variable maternal behavior early in life had little impact on the offspring's social interactions with other group members prior to puberty. In fact, the general affiliative and aggressive tendencies of crossfostered females in their first two years of life were more similar to those of their biological mothers than to those of their foster mothers (Maestripieri 2003b). There was, however, a significant negative correlation between CSF 5-HIAA and rates of scratching (Maestripieri et al. 2006b), suggesting that individuals with low CSF 5-HIAA were more anxious than those with high 5-HIAA (see Schino et al. 1991; Maestripieri et al. 1992, for the relation between scratching and anxiety). Differences in anxiety associated with serotonergic function may have contributed to some of the effects of exposure of variable parenting style that we observed after our female subjects reached puberty and gave birth for the first time.

Although there were no similarities between the maternal protectiveness scores of mothers and daughters, the maternal rejection rates of daughters closely resembled those of their mothers (Maestripieri et al. 2007). The resemblance was particularly strong for the crossfostered females and their foster mothers. This finding is consistent with a previously reported intergenerational correlation of maternal rejection rates in another population of rhesus macaques (Berman 1990) and suggests that this correlation is the result of early experience and not of genetic similarities between mothers and daughters. Although learning through direct experience with one's own mother and/or observations of maternal interactions with siblings may play a role in the intergenerational transmission of maternal rejection in macaques (Berman 1990), biological mechanisms are also important.

In our study, we found that the crossfostered females' CSF concentrations of 5HIAA were negatively correlated with their rates of maternal rejection, such that the individuals with lower CSF 5-HIAA exhibited higher rates of rejection with their infants (Maestripieri et al.2007). Therefore, exposure to variable rates of maternal rejection in infancy may affect the development of the brain serotonergic system, and variation in serotonergic function, in turn, may contribute to the expression of maternal rejection with one's own offspring later in life. Interestingly, a preliminary study by Lindell et al. (1997) found that the CSF 5-HIAA concentrations of rhesus macaque mothers were significantly correlated with those of their nine-month-old infants, but this study did not assess whether these correlations had a genetic or environmental nature. Evidence of both genetic and environmental effects on CSF concentrations of 5-HIAA and other monoamine metabolites was provided by Rogers et al. (2004) in a study of a large pedigreed population of baboons.

In addition to demonstrating the intergenerational transmission of maternal rejection rates, we found evidence for the intergenerational transmission of infant abuse. Specifically, about half of the females who were abused by their mothers early in life, whether crossfostered or non-crossfostered (all crossfostered females reared by abusive mothers were also abused by them), exhibited abusive parenting toward their first-born offspring, whereas none of the females reared by nonabusive mothers did (including those born to abusive mothers; Maestripieri 2005a). Moreover, the abused females, both crossfostered and non-crossfostered, who became abusive mothers had lower CSF 5-HIAA concentrations than the abused females who did not become abusive mothers (Maestripieri et al. 2006a). This finding suggests that experience-induced, long-term alterations in serotonergic function in females reared by abusive mothers contribute to the manifestation of abusive parenting in adulthood. It is possible that 
experience-induced reduction in serotonergic function results in elevated anxiety and impaired impulse control and that high anxiety and impulsivity increase the probability of occurrence of abusive parenting (e.g., Troisi and D'Amato 1991, 1994), perhaps in conjunction with social learning resulting from direct experience of abuse early in life or observation of abusive parenting displayed by one's own mother with siblings. The intergenerational transmission of infant abuse, however, is likely to be a complex process with multiple determinants and influences. The finding that abusive mothers were more likely to carry the $s$ allele of the serotonin transporter gene suggests that genetic variation in brain serotonergic function may play a role in the manifestation of abusive parenting and its transmission across generations. To understand the complex relationship between serotonin and abusive parenting, one must understand the relation between serotonin and maternal rejection as well as the relationship between maternal rejection and abuse.

\section{Serotonin and Maternal Behavior}

The brain serotonergic system is believed to play an important role in impulse control and in reducing the probability that risky, dangerous or aggressive behaviors will be expressed in response to internal pressures or external stimuli (e.g., Gollan and Coccaro 2005). Consistent with a large body of human research (e.g., Linnoila and Virkkunnen 1992), studies of rhesus macaques and vervet monkeys have shown that, in adult males, low levels of CSF 5-HIAA are associated with high impulsivity, risk-taking behavior and a propensity to engage in severe forms of aggression (see Higley 2003, for a review). In young males, low levels of CSF 5-HIAA are associated with earlier age of emigration from the natal group (e.g., Mehlman et al. 1995) and with the attainment of high dominance rank in adulthood (Fairbanks et al. 2004). Similar to the adult males, adult monkey females with low CSF 5-HIAA have been reported to be more likely to be wounded, to engage in violent aggression, and to be lower ranking than females with high CSF 5-HIAA (see Higley 2003 for review; but see Cleveland et al. 2004). Adult females with low CSF 5-HIAA also appear to be less socially oriented, spending more time alone, grooming less, and having fewer conspecifics in close proximity (Cleveland et al. 2004; rhesus macaque abusive mothers fit this behavioral profile quite well; see Maestripieri 1998b). Westergaard et al. (2003) also reported that the infants born to adult rhesus females with low CSF 5-HIAA concentrations are more likely to die within a year after birth than infants born to females with high CSF 5-HIAA concentrations.

Early studies of serotonin and maternal behavior in monkeys reported that mothers with low CSF 5-HIAA were more protective and restrictive, and that their infants spent more time in contact with them, than mothers with high CSF 5-HIAA (Lindell et al. 1997; Fairbanks et al. 1998). Cleveland et al. (2004) found no relationship between CSF 5-HIAA and maternal behavior in the first few post-partum days, but on post-partum days 15 and 20, females with low CSF 5-HIAA broke contact and left their infants less frequently than females with high CSF 5-HIAA. A preliminary study in our laboratory reported a positive correlation between CSF 5-HIAA concentrations measured during pregnancy and maternal rejection behaviors in the first post-partum month in multiparous females (Maestripieri et al. 2005). Our more recent work involving multiple measurements of CSF 5-HIAA during development, however, reported a negative correlation between CSF 5-HIAA and maternal rejection among first-time 
mothers (Maestripieri et al. 2007). Taken together, these studies support the notion that variation in serotonergic function can contribute to the expression of differences in maternal behavior, although the relationship between serotonin and primate maternal behavior is not yet fully understood.

Although serotonin might affect maternal motivation through its actions on oxytocin or prolactin release, serotonin and other monoamines are generally viewed as having aspecific effects on emotionality, motivation, or memory rather than specific effects on parentally motivated behaviors (Insel and Winslow 1998; Numan and Insel 2003). Research with rodents has established a strong link between anxiety/impulsivity and maternal aggression (e.g., Lonstein and Gammie 2002), but the emotional substrate of rodent maternal behavior is not well established (but see Weller et al. 2003).

Emotions, however, play a fundamental role in the regulation of maternal behavior in nonhuman primates and humans (Dix 1991; Pryce 1992; Maestripieri 1999). Emotions can be powerful elicitors of maternal behavior and play a crucial role in mediating the impact of the surrounding environment on the mother-infant dyad. For example, Pryce (1992) argued that two emotional systems, the attraction/arousal system and the anxiety system, play a central role in the regulation of primate maternal behavior. The attraction-arousal system involves the activation of positive emotions (e.g., excitement or joy) that elicit nurturing maternal behavior, whereas the anxiety system involves the activation of negative emotions (e.g., anxiety and fear) that elicit protective or rejecting maternal behaviors. Whereas the postpartum period is associated with lower reactivity to stress in rodents ( $\mathrm{Tu}$ et al. 2006; but see Deschamps et al. 2003), pregnancy and the postpartum period in nonhuman primates and humans are characterized by high emotional instability and reactivity. For example, high cortisol levels and high arousability in the early postpartum period have been associated with greater sensitivity to infant cues and greater maternal responsiveness in humans (Fleming et al. 1987, 1997; see also Maestripieri et al. 2008, for rhesus macaques). Interestingly, etiological theories of postpartum psychosis based on estrogen's interaction with serotonin systems have been proposed (Fink and Sumner 1996). For example, it has been shown that variation in the SERT genotype affects susceptibility to bipolar affective puerperal psychosis (Coyle et al. 2000).

Motherhood is a psychologically stressful condition in human and nonhuman primates. In rhesus macaques, the first few months of an infant's life result in a number of anxiety-eliciting situations for the mother (Maestripieri 1993a). There are marked individual differences in anxiety among rhesus mothers, and such differences translate into differences in maternal style (Maestripieri 1993b). Maternal anxiety has also been implicated in the etiology of infant abuse (Troisi and D'Amato 1984, 1991, 1994). Although the role of emotionality, and particularly of impulsivity, in primate maternal behavior is still poorly understood, it is possible that impulsivity affects how primate mothers interact with their infants, and that high impulsivity is expressed as high rejection rates as well as, as other studies suggest, greater maternal protectiveness. Our recent findings suggest that variation in impulsivity and maternal rejection originates, at least in part, from early experience and that there may be causal relationships between these two variables, such that high rates of maternal rejection result in low serotonergic function, which in turn results in high rates of maternal rejection later in life.

Maternal rejection also has a complex relation with infant abuse, perhaps not dissimilar from the relationship between child neglect and abuse in humans. Although 
abusive parenting in monkeys is probably maladaptive (Maestripieri 1998b), maternal rejection is a behavior that belongs to the normal maternal repertoire and is used by mothers to limit the amount of time spent by infants in bodily and nipple contact, thus encouraging the infant's social and nutritional independence (e.g., Simpson and Simpson 1985). Abusive parenting in rhesus macaques co-occurs with high rates of maternal rejection. Abusive mothers begin rejecting their infants shortly after birth (rejection normally begins after three to four weeks) and continue to do so at much higher rates than nonabusive mothers (Maestripieri 1998b; McCormack et al. 2006). Although we found no direct effects of infant abuse on CSF 5-HIAA, the observed significant effects of maternal rejection on CSF 5-HIAA were likely driven by abused infants, who were exposed to much higher levels of rejection than nonabused infants. Rejection occurs more frequently than abuse and, although it does not cause physical harm to the infants, it may be even more psychologically traumatic than abuse. Interestingly, human studies have found that child neglect tends to have stronger and more consistent effects on brain structure and function in maltreatment victims than physical abuse does, although both are transmitted across generations (e.g., Glaser 2000; DeBellis 2005). Although social learning probably plays an important role in the intergenerational transmission of both maternal rejection and abuse in monkeys, our results suggest that rejection is more likely than abuse to cause long-term alterations in neuroendocrine and emotional functioning and that these alterations may contribute to the expression of both rejecting and abusive parenting later in life.

Acknowledgements. The research reviewed in this chapter was supported by NIH and involved the participation of many collaborators and assistants, including Richelle Fulks, Anne Graff, Dee Higley, Stephen Lindell, Kai McCormack, Nancy Megna, Timothy Newman, and Mar Sanchez.

\section{References}

Bardi M, Huffman MA (2006) Maternal behavior and maternal stress are associated with infant behavioral development in macaques. Dev Psychobiol 48:1-9

Bardi M, Bode AE, Ramirez SM, Brent LY (2005) Maternal care and the development of the stress response. Am J Primatol 66:263-278

Barr CS, Newman TK, Shannon C, Parker C, Dvoskin RL, Becker ML, Schwandt M, Champoux M, Lesch KP, Goldman D, Suomi SJ, Higley JD (2004a) Rearing condition and rh5-HTTLPR interact to influence LHPA-axis response to stress in infant macaques. Biol Psychiat 55:733738

Barr CS, Newman TK, Lindell S, Shannon C, Champoux M, Lesch KP, Suomi SJ, Higley JD (2004b) Interaction between serotonin transporter gene variation and rearing condition in alcohol preference and consumption in female primates. Arch Gen Psychiat 61:1146-1152

Bennett AJ, Lesch KP, Heils A, Long JC, Lorenz JG, Shoaf SE, Champoux M, Suomi SJ, Linnoila MV, Higley JD (2002) Early experience and serotonin transporter gene variation interact to influence primate CNS function. Mol Psychiat 7:118-122

Berman CM (1984) Variation in mother-infant relationships: traditional and nontraditional factors. In: Small MF (ed) Female primates: studies by women primatologists. Alan Liss, New York, pp 17-36

Berman CM (1990) Intergenerational transmission of maternal rejection rates among freeranging rhesus monkeys. Anim Behav 39:329-337

Caspi A, McClay J, Moffitt TE, Mill J, Martin J, Craig IW, Taylor A, Poulton R (2002) Role of genotype in the cycle of violence in maltreated children. Science 297:851-854 
Caspi A, Sugden K, Moffitt TE, Taylor A, Craig IW, Harrington H, McClay J, Mill J, Martin J, Braithwaite A, Poulton R (2003) Influence of life stress on depression: Moderation by a polymorphism in the 5-HTT gene. Science 301:386-389

Champoux M, Coe CL, Schanberg SM, Kuhn CM, Suomi SJ (1989) Hormonal effects of early rearing conditions in the infant rhesus monkey. Am J Primatol 19:111-117

Cleveland A, Westergaard GC, Trenkle MK, Higley JD (2004) Physiological predictors of reproductive outcome and mother-infant behaviors in captive rhesus macaque females (Macaca mulatta). Neuropsychopharmacology 29:901-910

Coyle N, Jones I, Robertson E, Lendon C, Craddock N (2000) Variation at the serotonin transporter gene influences susceptibility to bipolar affective puerperal psychosis. Lancet 356:1490-1491

DeBellis MD (2005) The psychobiology of neglect. Child Maltreatment 10:150-172

Deschamps S, Woodside B, Walker CD (2003) Pups' presence eliminates the stress hyporesponsiveness of early lactating females to a psychological stress representing a threat to the pups. J Neuroendocrinol 15:486-497

Dix T (1991) The affective organization of parenting: Adaptive and maladaptive processes. Psych Bull 110:3-25

Fairbanks LA (1989) Early experience and cross-generational continuity of mother-infant contact in vervet monkeys. Dev Psychobiol 22:669-681

Fairbanks LA (1996) Individual differences in maternal styles: causes and consequences for mothers and offspring. Adv Study Behav 25:579-611

Fairbanks LA (2003) Parenting. In: Maestripieri D (ed) Primate psychology. Harvard University Press, Cambridge, MA, pp 144-170

Fairbanks LA, McGuire MT (1987) Mother-infant relationships in vervet monkeys: response to new adult males. Intl J Primatol 8:351-366

Fairbanks LA, McGuire MT (1988) Long-term effects of early mothering behavior on responsiveness to the environment in vervet monkeys. Dev Psychobiol 21:711-724

Fairbanks LA, McGuire MT (1993) Maternal protectiveness and response to the unfamiliar in vervet monkeys. Am J Primatol 30:119-129

Fairbanks LA, Melega WP, McGuire MT (1998) CSF 5-HIAA is associated with individual differences in maternal protectiveness in vervet monkeys. Am J Primatol 45:179-180 (abstract)

Fairbanks LA, Jorgensen MJ, Huff A, Blau K, Hung Y, Mann JJ (2004) Adolescent impulsivity predicts adult dominance attainment in male vervet monkeys. Am J Primatol 64:1-17

Fink G, Sumner BEH (1996) Estrogen and mental state. Nature 383:306

Fleming AS, Steiner M, Anderson V (1987) Hormonal and attitudinal correlates of maternal behavior during the early postpartum period in first-time mothers. J Reprod Inf Psychol 5:193-205

Fleming AS, Steiner M, Corter C (1997) Cortisol, hedonics, and maternal responsiveness in human mothers. Horm Behav 32:85-98

Gardner KL, Thrivikraman KV, Lightman SL, Plotsky PM, Lowry CA (2005) Early life experience alters behavior during defeat: focus on serotonergic systems. Neuroscience 136:181-191

Glaser D (2000) Child abuse and neglect and the brain: A review. J Child Psychol Psychiat 41:97116

Gollan JK, Lee R, Coccaro EF (2005) Developmental psychopathology and neurobiology of aggression. Dev Psychopathol 17:1151-1171

Higley JD (2003) Aggression. In: Maestripieri D (ed) Primate psychology. Harvard University Press, Cambridge, MA, pp 17-40

Higley JD, Suomi SJ, Linnoila M (1992) A longitudinal study of CSF monoamine metabolite and plasma cortisol concentrations in young rhesus monkeys: Effects of early experience, age, sex and stress on continuity of interindividual differences. Biol Psychiat 32:127-145

Hinde RA, Spencer-Booth Y (1971) Towards understanding individual Ddifferences in rhesus mother-infant interaction. Anim Behav 19:165-173

Insel TR, Winslow JT (1998) Serotonin and neuropeptides in affiliative behaviors. Biol Psychiat 44:207-219 
Kraemer GW, Ebert MH, Schmidt DE, McKinney WT (1989) A longitudinal study of the effect of different social rearing conditions on cerebrospinal fluid norepinephrine and biogenic amine metabolites in rhesus monkeys. Neuropsychopharmacol 2:175-189

Ladd CO, Owens MJ, Nemeroff CB (1996) Persistent changes in corticotropin-releasing factor neuronal systems induced by maternal deprivation. Endocrinology 137:1212-1218

Lesch KP, Bengel D, Heils A, Sabol SZ, Greenberg BD, Petri S, Benjamin J, Muller C, Hamer D, Murphy D (1996) Association of anxiety-related traits with a polymorphism in the serotonin transporter gene regulatory region. Science 274:1527-1531

Lindell SG, Higley JD, Shannon C, Linnoila M (1997) Low levels of CSF 5-HIAA in female rhesus macaques predict mother-infant interaction patterns and mother's CSF 5-HIAA correlates with infant's CSF 5-HIAA. Am J Primatol 42:129 (abstract)

Linnoila VM, Virkkunen M (1992) Aggression, suicidality, and serotonin. J Clin Psychiat 53:46-51

Lonstein JS, Gammie SC (2002) Sensory, hormonal, and neural control of maternal aggression in laboratory rodents. Neurosci Biobehav Rev 26:869-888

Maestripieri D (1993a) Maternal anxiety in rhesus macaques (Macaca mulatta). I. Measurement of anxiety and identification of anxiety-eliciting situations. Ethology 95:19-31

Maestripieri D (1993b) Maternal anxiety in rhesus macaques (Macaca mulatta). II. Emotional bases of individual differences in mothering style. Ethology 95:32-42

Maestripieri D (1998a) Social and demographic influences on mothering style in pigtail macaques. Ethology 104:379-385

Maestripieri D (1998b) Parenting styles of abusive mothers in group-living rhesus macaques. Anim Behav 55:1-11

Maestripieri D (1999) The biology of human parenting: Insights from nonhuman primates. Neurosci Biobehav Rev 23:411-422

Maestripieri D (2003a) Attachment. In: Maestripieri D (ed) Primate psychology. Harvard University Press, Cambridge, MA, pp 108-143

Maestripieri D (2003b) Similarities in affiliation and aggression between cross-fostered rhesus macaque females and their biological mothers. Dev Psychobiol 43:321-327

Maestripieri D (2005a) Early experience affects the intergenerational transmission of infant abuse in rhesus monkeys. Proc Natl Acad Sci USA 102:9726-9729

Maestripieri D (2005b) Effects of early experience on female behavioural and reproductive development in rhesus macaques. Proc R Soc Lond B 272:1243-1248

Maestripieri D, Carroll KA (1998a) Child abuse and neglect: Usefulness of the animal data. Psych Bull 123:211-223

Maestripieri D, Carroll KA (1998b) Risk factors for infant abuse and neglect in group-living rhesus monkeys. Psych Sci 9:65-67

Maestripieri D, Schino G, Aureli F, Troisi A (1992) A modest proposal: displacement activities as an indicator of emotions in primates. Anim Behav 44:967-979

Maestripieri D, Wallen K, Carroll KA (1997) Infant abuse runs in families of group-living pigtail macaques. Child Ab Negl 21:465-471

Maestripieri D, Lindell SG, Ayala A, Gold PW, Higley JD (2005) Neurobiological characteristics of rhesus macaque abusive mothers and their relation to social and maternal behavior. Neurosci Biobehav Rev 29:51-57

Maestripieri D, Higley JD, Lindell SG, Newman TK, McCormack K, Sanchez MM (2006a) Early maternal rejection affects the development of monoaminergic systems and adult abusive parenting in rhesus macaques. Behav Neurosci 120:1017-1024

Maestripieri D, McCormack K, Lindell SG, Higley JD, Sanchez MM (2006b) Influence of parenting style on the offspring's behavior and CSF monoamine metabolites levels in crossfostered and noncrossfostered female rhesus macaques. Behav Brain Res 175:90-95

Maestripieri D, Lindell SG, Higley JD (2007) Intergenerational transmission of maternal behavior in rhesus monkeys and its underlying mechanisms. Dev Psychobiol 49:165-171

Maestripieri D, Hoffman CL, Fulks R, Gerald MS (2008) Plasma cortisol responses to stress in lactating and nonlactating female rhesus macaques. Horm Behav, 53:170-176 
McCormack KM, Sanchez MM, Bardi M, Maestripieri D (2006) Maternal care patterns and behavioral development of rhesus macaque abused infants in the first 6 months of life. Dev Psychobiol 48:537-550

Mehlman PT, Higley JD, Faucher I, Lilly AA, Taub DM, Vickers J, Suomi SJ, Linnoila M (1995) Correlation of CSF 5-HIAA concentration with sociality and the timing of emigration in free-ranging primates Am J Psychiat 152:907-913

Numan M, Insel TR (2003) The neurobiology of parental behavior. Springer, New York

Pryce CR (1992) A comparative systems model of the regulation of maternal motivation in mammals. Anim Behav 43:417-441

Rogers J, Martin LJ, Comuzzie AG, Mann JJ, Manuck SB, Leland M, Kaplan JR (2004) Genetics of monoamine metabolites in baboons: overlapping sets of genes influence levels of 5-hydroxyindolacetic acid, 3-hydroxy-4-methoxyphenylglycol, and homovanillic acid. Biol Psychiat 55:739-744

Schino G, Troisi A, Perretta G, Monaco V (1991) Measuring anxiety in nonhuman primates: Effect of lorazepam on macaque scratching. Pharm Biochem Behav 38:889-891

Schino G, D'Amato FR, Troisi A (1995) Mother-infant relationships in Japanese macaques: Sources of interindividual variation. Anim Behav 49:151-158

Schino G, Speranza L, Troisi A (2001) Early maternal rejection and later social anxiety in juvenile and adult Japanese macaques. Dev Psychobiol 38:186-190

Shannon C, Schwandt ML, Champoux M, Shoaf SE, Suomi SJ, Linnoila M, Higley JD (2005) Maternal absence and stability of individual differences in CSF5-HIAA concentrations in rhesus monkey infants. Am J Psychiat 162:1658-1664

Simpson MJA (1985) Effects of early experience on the behaviour of yearling rhesus monkeys (Macaca mulatta) in the presence of a strange object: classification and correlation approaches. Primates $26: 57-72$

Simpson AE, Simpson MJA (1985) Short-term consequences of different breeding histories for captive rhesus macaque mothers and young. Behav Ecol Sociobiol 18:83-89

Simpson MJA, Datta SB (1990) Predicting infant enterprise from early relationships in rhesus macaques. Behaviour 116:42-63

Simpson MJA, Gore MA, Janus M, Rayment FDG (1989) Prior experience of risk and individual differences in enterprise shown by rhesus monkey infants in the second half of their first year. Primates 30:493-509

Tanaka I (1989) Variability in the development of mother-infant relationships among free-ranging Japanese macaques. Primates 30:477-491

Troisi A, D'Amato FR (1984) Ambivalence in monkey mothering: infant abuse combined with maternal possessiveness. J Nerv Ment Dis 172:105-108

Troisi A, D'Amato FR (1991) Anxiety in the pathogenesis of primate infant abuse: A pharmacological study. Psychopharmacology 103:571-572

Troisi A, D'Amato FR (1994) Mechanisms of primate infant abuse: the maternal anxiety hypothesis. In: Parmigiani S, vom Saal F (eds) Infanticide and parental care. Harwood, London, pp 199-210

Tu MT, Lupien SJ, Walker C-D (2006) Measuring stress in postpartum mothers: Perspectives from studies in human and animal populations. Stress 8: 19-34

Vochteloo JD, Timmermans PJA, Duijghuisen JAH, Vossen JMH (1993) Effects of reducing the mother's radius of action on the development of mother-infant relationships in longtailed macaques. Anim Behav 45:603-612

Weller A, Leguisamo AC, Towns L, Ramboz S, Bagiella E, Hofer M, Hen R, Brunner D (2003) Maternal effects in infant and adult phenotypes of 5HT(1A) and 5HT(1B) receptor knockout mice. Dev Psychobiol 42:194-205

Westergaard GC, Cleveland A, Trenkle MK, Lussier ID, Higley JD (2003) CSF 5-HIAA concentrations as an early screening tool for predicting significant life history outcomes in female specific-pathogen-free (SPF) rhesus macaques (Macaca mulatta) maintained in captive breeding groups. J Med Primatol 32:95-104 